Z. Klin. Chem. Klin. Biochem.

12. Jg. 1974, S. $530-534$

\title{
In Vivo Observations Concerning the Relation between Metabolism, Regulation and Biochemical Oscillations in the Glucose Concentrations of Venous Blood
}

\author{
By J. D. Kruse-Jarres ${ }^{1}$ ), M. Karpf and L. Quaas ${ }^{2}$ ) \\ Klinisch-chemische und experimentelle Laboratorien der Chirurgischen Universitätsklinik (Dir.: Prof. Dr. \\ M. Schwaiger) Freiburg
}

(Eingegangen am 10. April/19. Juli 1974)

The glucose concentration in the blood represents a metabolic state characterised in all living by variations that can be reliably recorded. It therefore is a parameter suitable for observation over prolonged periods for the classification of physiological oscillations. By aid of the continuous in vivo technique oscillations are observed in 3 different fields of indication:

1. high-frequency oscillations after acute metabolic disturbances in ischaemia,

2. medium-frequency oscillations after experimental hyperglycaemia in the intravenous glucose tolerance test, and

3. low-frequency oscillations in the form of diurnal or circadian rhythms.

The described oscillations are interpreted not only as an indication of counter-regulation and feed-back but as principal features of individual-specific, self-induced vibrations.

Die Glucosekonzentration im Blut repräsentiert einen metabolischen Zustand, dẹ in allen lebenden Systemen durch gut rẹgistrierbare Schwankungen gekennzeichnet ist. Sie ist daher ein geeigneter Parameter, um im Zusammenhang mit der Einordnung physiologischer Oscillationen über längere Zeitabstände beobachtet zu werden. Mit Hilfe der kontinuierlichen in-vivo-Analyse wird dies in drei verschiedenen Indikationsräumen getan: es handelt sich um

1. die hochfrequenten Oszillationen nach akuten Stoffwechselstörungen durch Ischämie,

2. die mittelfrequenten Oszillationen nach experimenteller Hyperglykaemie im intravenösen Glucose-Toleranz-Test, und

3. die niederfrequenten Oszillationen in Form diurnaler und circadianer Rhythmen.

Die beschriebenen Oszillationen werden nicht nur als Zeichen von Gegenregulation und Rückkopplung, sondern als Merkmale individual-spezifischer, selbsterregter Schwingungen interpretiert.

Continuous recording of physical parameters in biological systems has been in use for decades. Electrocardiography, electroencephalography, electromyography, pulse rate and pressure measurements, to name only a few, are obvious parameters for continuous observation. The observed alterations of physical values in a unit of time give rise clinically to therapeutic measures, as conversely the effect of therapy finds an expression in the alferation of physical parameters. These alterations of physical parameters however are based nearly always in primarily biochemical processes. These in turn are subject to periodic phenomena like diurnal or circadian rhythms, just as they are subject to regular oscillations of other frequences as described for the first time in 1955 with the dark-reaction of photosynthesis (1). Since then a number of biological systems have been described where border cycle behaviour and oscillations were recorded as external characteristics of so-called feed-back mechanisms (2-5).
A typical and almost universal biochemical chain of processes is glycolysis, closely investigated in this respect by Hess \& Boiteux (6). This chemical system consists of a series of coupled reactions with cataly tic feedback mechanisms. Once such a cycle in a biochemical system is set in motion it persists. The reaction partners act in such a way that they protect each other and a new type of balance develops which may show oscillatory behaviour.

Other evidence shows that cells also manifest on oscillatory behaviour that takes place on a higher organisation level than is the case in glycolysis $(7,8)$. The vital rhythm of a cell is closely connected with the

1) Delivered in extracts at the annual meeting of Deutsche Gesellschaft für Klinische Chemie, Hannover 13. 9. 1973.

$\left.{ }^{2}\right)$ Essential parts of the present paper are submitted by $L$. Quaas as dissertation of the Medizinische Fakultät of the University Freiburg. 
periodic protein synthesis, growth and cell division. The cycles can be synchronised for the whole cell population. Thus arises a temporary organization as seen in the case of living biochemical systems. Moreover the origin of such linear oscillations is distinguished from nonlinear oscillations of exogenous origin by its own regularity and physiological periodicity which need not necessarily show a rigid frequency. The glucose concentrations in the blood represent a mainly metabolic state characterised in all living systems by variations that can be reliably recorded. Glucose concentration therefore is a parameter suitable for observation over long periods in connexion with the classification of physiological oscillations. Observations will be reported in the following which were made in man and animals in the framework of continuous recordings of glucose long-term profiles.

\section{Methods}

A method described by $\operatorname{Kawerau}(9,10)$ for the continuous in vivo recording of the blood glucose was chosen; this offers advantages for the observation of dynamic events. In principle blood is continuously taken from arm or leg vein of the test person via a double-calibrated needle by means of a pump. The unintermittent analysis is made by an Auto-Analyzer. At the same time, heparin is driven through the outer lumen of the needle as far as the tip of the inner suction catheter (fig. 1). From this mixing zone the blood is aspirated through a pump in a constant dilution. The patient himself need not be heparinised. The needle is left in the vein until the end of the test. The course of the analysis is based on the familiar principle of the AutoAnalyzer and the glucose analysis is performed according to the Glucose oxidase/Peroxidase method with $o$ Dianisidine as chromogen (11). The continuously aspirated blood stream is measured and recorded continuously. The blood loss is $6 \mathrm{ml}$ per hour.

\section{Test conditions}

Depending on the different types of oscillations the test material was as follows:

High-frequency oscillations are reported in 15 adult shephard dogs and in 25 voluntary, healthy test persons aged $20-30$ years.
The necessary anaesthesia was obtained with oxygen-nitrous oxide-halothane.

1050 continuously recorded, intravenous glucose tolerance tests supplied the foundation to the interpretation of medium-frequency oscillations.

For the assessment of low-frequency oscillations, 52 glucose curves were unintermittently recorded on average for 12 hours $(4-36 h)$ in healthy test persons $(n=20)$, diabetics $(n=14)$, and unconscious, polytraumated patients under standard drip infusion $(n=18)$. The infusion therapy consisted of:

$2000 \mathrm{ml} / \mathrm{d}$ Aminomel LX 6 (Boehringer Mannheim)

$822 \mathrm{mmol} / 1$ Xylitol

$60 \quad \mathrm{~g} / 1 L$-amino acids

$2.5 \mathrm{~g} / 1 L$-malic acid

$35 \mathrm{mmol} / 1$ sodium

$25 \mathrm{mmol} / 1$ potassium

$1.25 \mathrm{mmol} / 1$ magnesium

$43 \mathrm{mmol} / 1$ chloride

$18 \mathrm{mmol} / 1$ acetate

+ additionally

$444 \mathrm{mmol} / \mathrm{l} D$-glucose

$+1000 \mathrm{ml} / \mathrm{d}$ Sterofundin AZ (Braun Melsungen)

$153 \mathrm{mmol} / 1$ glucose

$139 \mathrm{mmol} / 1$ fructose

$50 \mathrm{mmol} / 1$ sodium

$50 \mathrm{mmol} / 1$ potassium

\section{Results}

1. High-frequency oscillations in man and dog after acute metabolic disturbance with observation periods up to 6 hours:

In dogs and test volunteers a tourniquet with 600 Torr was applied to a lower extremity, under oxygen-nitrous oxide-halothane anaesthesia and controlled respiration, for the purpose of studying the metabolism in ischaemic tissue (fig. 2): As early as $15 \mathrm{~min}$ after application of the tourniquet great irregularities develop in the glucose curves, and there are distinct venous and arterial $\mathrm{pH}$ changes. A part from the tendency of the curves to fall, the decrease of amplitude is noticeable until the lower glucose level is established within the observation period

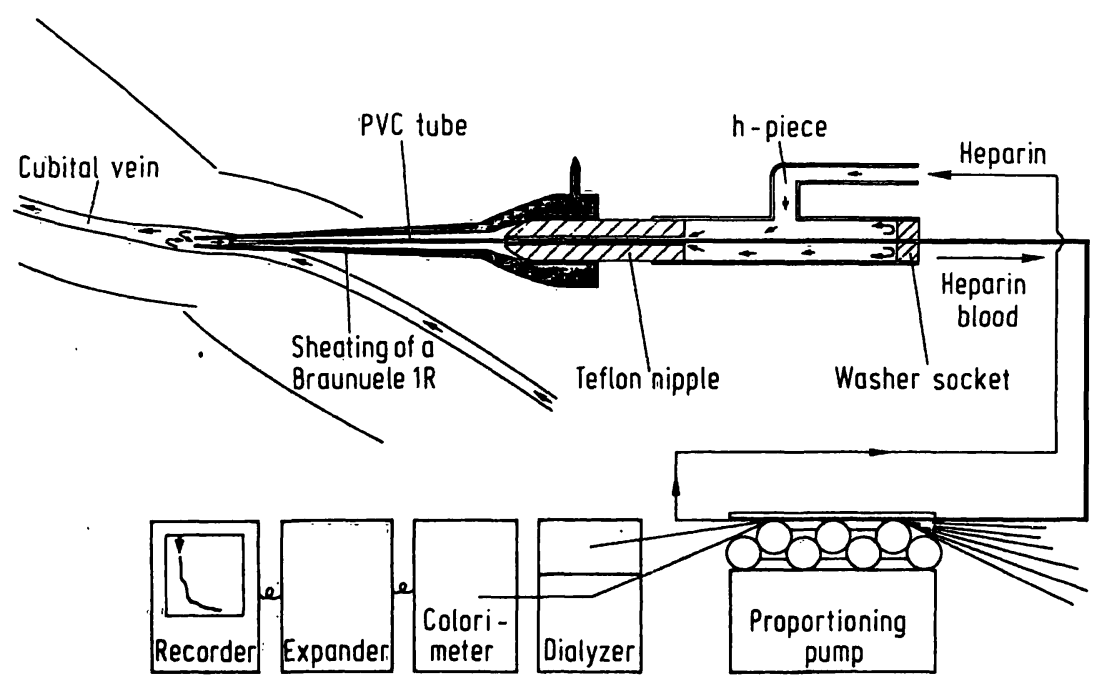

Fig. 1. Puncture needle with a double lumen aspirates blood through a pump in a constant dilution with heparin. 


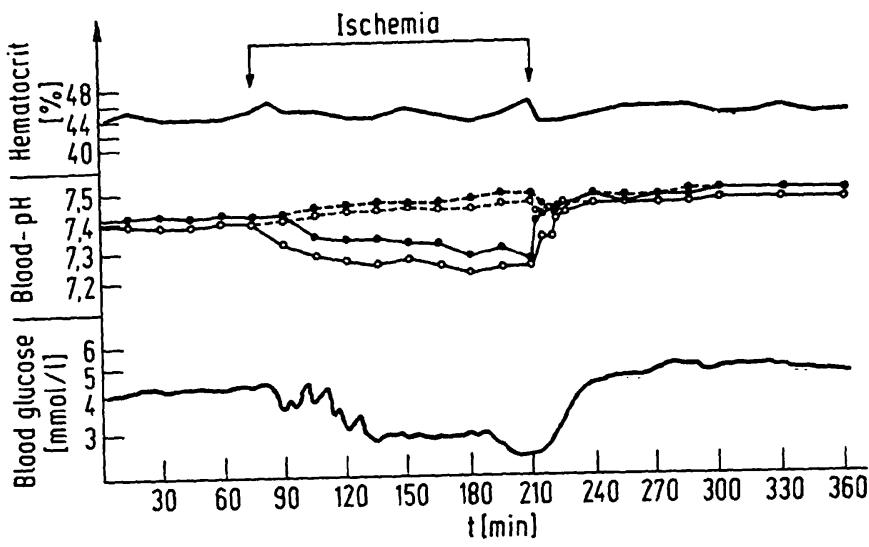

Fig. 2. High-frequency oscillations during a $2 \mathrm{hrs}$. tourniquet to a lower extremity of a dog (26.5 kg, 2 years)

above: hematocrit (\%)

middle: arterial $(\bullet-0)$ and venous $(0-0)$ blood $\mathrm{pH}$

below: blood glucose ( $\mathrm{mmol} / \mathrm{l})$

of 2 hours up to the release of the tourniquet. This behaviour of the blood glucose in the ischaemic extremity in contrast to the control extremity proves to be the same in man and dog. The initial glucose concentration is $6.84 \mathrm{mmol} / 1$. After 2 hours ischaemia a significant hypoglycaemia of $4.74 \mathrm{mmol} / 1$ appears. The values increase markedly during the first 5 postischaemic minutes to $8.06 \mathrm{mmol} / 1$. This hyperglycaemia in the ischaemic extremity recedes during the further course. After 15 min relaxation the glucose concentration was $7.54 \mathrm{mmol} / 1$, and $120 \mathrm{~min}$ later it decreased to $6.34 \mathrm{mmol} / \mathrm{l}$. In the control extremity an increase to $7.97 \mathrm{mmol} / \mathrm{l}$ was found which was still determinable after the relaxation period.

Similar oscillations, though not very marked, occur after administration of insulin (fig. 3 ) as far as the metabolic state of the manifest diabetic allows smaller doses of

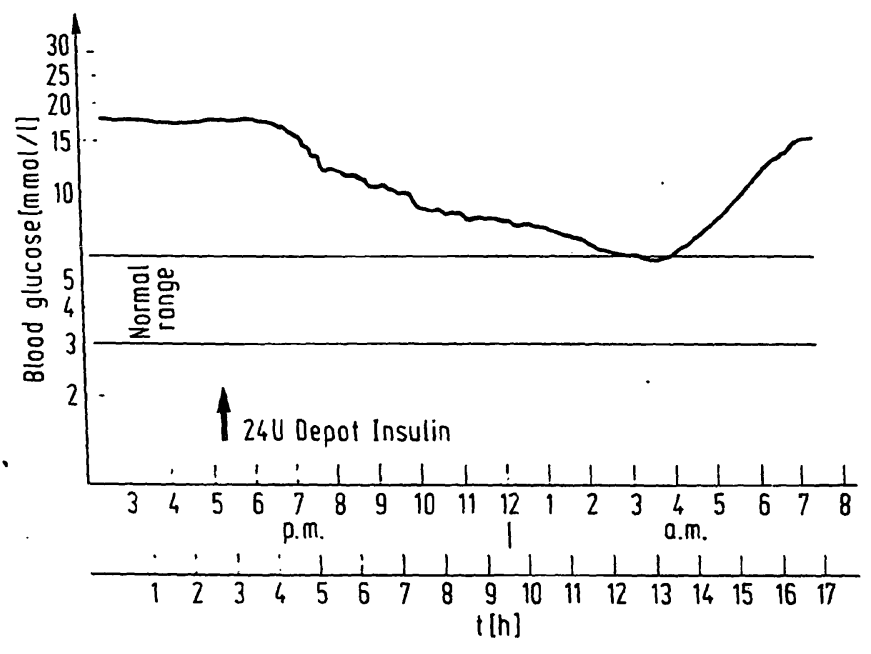

Fig. 3. Patient $\mathrm{K}$. Sp. ( 45 years, $98 \mathrm{~kg}$ ) with juvenile diabetes mellitus. $24 \mathrm{U}$ depot insulin were administered s. c. at 5 p. m. externally administered insulin to influence the glucose homoeostasis which is switched to a steady higher level. After the administration of sulfonylurea to lower the blood glucose, such oscillations were not seen in people with a normal metabolism, or in diabetics.

2. Medium-frequency oscillations after experimental hyperglycaemia in the intravenou's glucose tolerance test in man with observation periods up to 20 hours:

In $85 \%$ of potential diabetics with a history and family history, highfrequency oscillations are found during the exponential glucose administration after intravenous administration of glucose. These oscillations however so far admit no interpretative classification with regard to periodicity or amplitude (fig. 4). Their amplitudes from peak to peak are on average $1.1 \mathrm{mmol} / \mathrm{l}$ and lie definitely outside the range of error of the chemical method of glucose estimation (SEM 0.036).

There are however additional diminishing oscillations to be found, of a type suggesting a changeover to a new balance and resembling oscillations induced by endogenous factors. Their amplitudes are significant but the significance decreases with time as long as further exogenous influences are present.

For further studies unconscious patients in the intensive care unit were observed (fig. 5) who were under constant continuous drip infusion. More particularly the glucose solution for the supply of energy was running in constantly. Under this therapy there developed a picture of definite glucose oscillations which could not have been of exogenous origin. An endogenous stimulation about 7 a.m. emerges clearly from the rest of the picture, with the effect of an initial frequency of 2.4 hours. This suggests an autonomous re-levelling of the blood glucose which had fallen during the night. It is, indeed, conspicious that the low amplitudes in comparison with those during the night do not fit into the

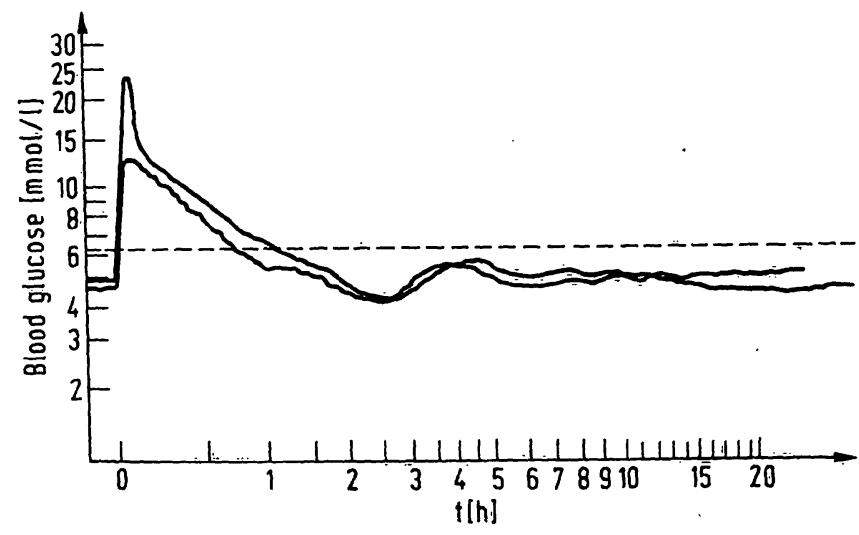

Fig. 4. High-frequency oscillations within the first hour after i. v. glucose administration $(0.33 \mathrm{~g} / \mathrm{kg})$ in a "potential diabetic" (lower curve) in contrast to a "normal person" (upper curve) and diminishing medium-frequency oscillations. Observation period up to 20 hours. 


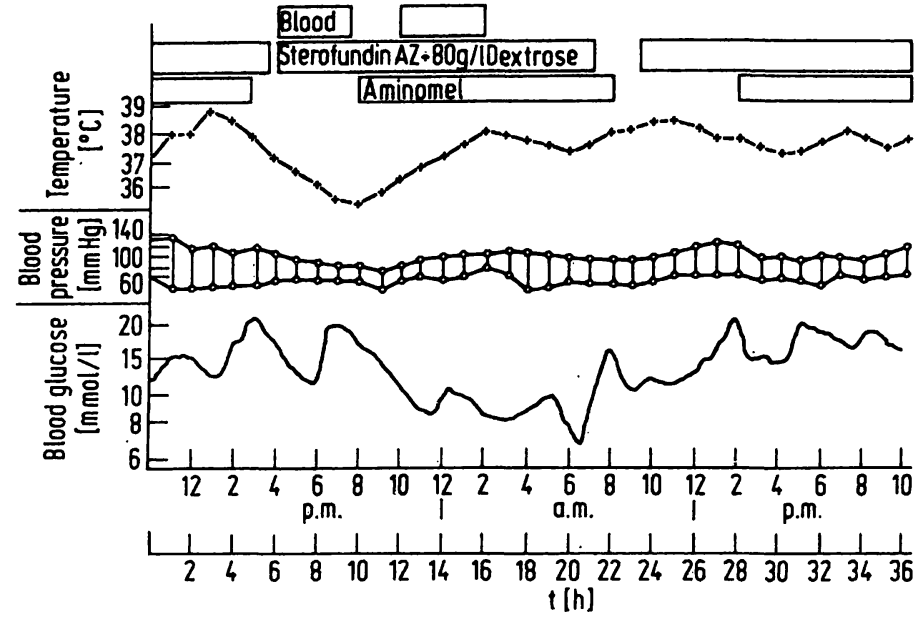

Fig. 5. Blood glucose (below), blood pressure (middle) and temperature (above) in a 43 years old unconscious patient after a severe craniocerebral trauma with posttraumatic hydrocephalus and medio-basal bleeding.

Observation period up to 36 hours.

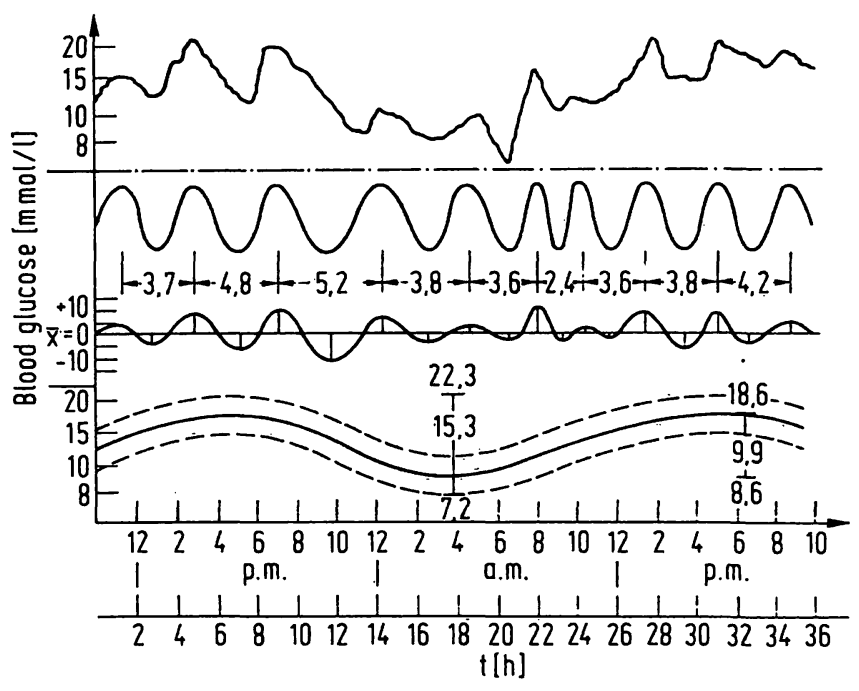

Fig. 6. Blood glucose of the same patient (see fig. 5) (above), balance by averaging the maximal and minimal values of amplitude (above/middle), oscillations about a statistical average (middle/below), resulting circadian rhythms (below).

schema of diminishing oscillations to be expected after a single stimulation. There must therefore be more than one mechanism in operation.

3. Low-frequency oscillations in the form of socalled diurnal rhythms in test subjects and unconscious patients after severe brain and skull trauma in observation periods up to 36 hours:

If the oscillations with frequencies of 2.4 to 5.2 hours are balanced by averaging the maximal and minimal values of amplitude (fig. 6), there emerges a definite diumal rhythm with a maximum in the late afternoon and a minimum during the night. This rhythm is also recognisable in so-called normal test subjects, whether they are fasting (fig. 7a) or taking their normal food (fig. 7b).

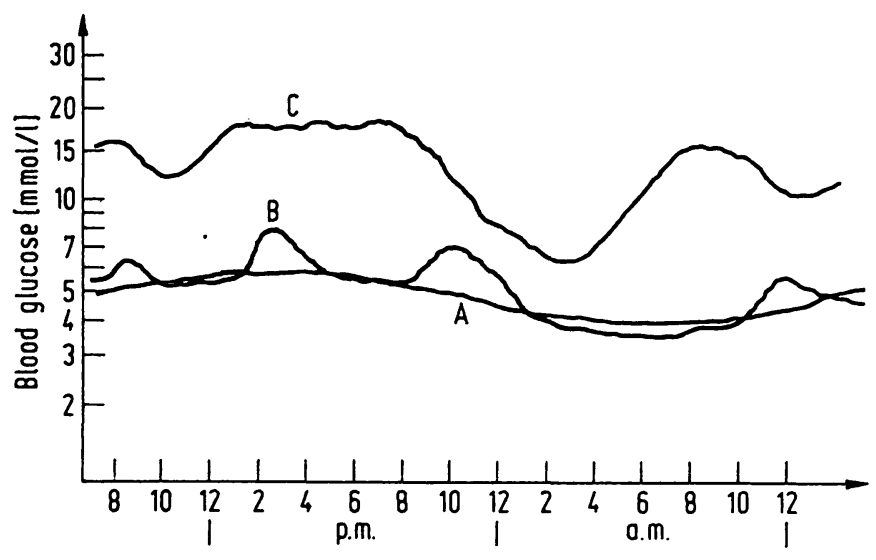

Fig. 7. Blood glucose (continuously)

a) "Normal" fasting test person (K. E., male, 24 years)

b) same person taking his normal food

c) insulin dependent diabetic (I. F., female, 62 years).

\section{Discussion}

The inconstancy of the glucose rhythm in one and the same subject indicates that the glucose system is regulated by some periodic impulse originator with a frequency of less than a period in 1.5 hours or a small multiple of this or by some other outside processes not yet discovered. Whatever the process may be, it cannot be connected with the circadian variations or with the intake of food and it is always found at the same time of day, i.e. always in the same phase of the circadian rhythm process. As shown by Halberg's considerations with reference to the adrenal cycle and by Aschoff and his "Phasen-Karten" it is no matter of passive reaction of the organism to the environmental influences changing with the rotation of the earth, but of an endogenous, genetically fixed periodicity characterized by selfinduced vibrations.

An attractive basis for the interpretation of oscillations in living systems would be to assume that for an abstract system, neither traditional nor linear, one single stable mode is created by a border cycle. This explanation is too simple. It seems more likely to connect the described processes with thermodynamic forces of our organism as to be seen in the demonstration of highfrequency oscillations in acute ischaemia: After a 2 hours ischaemia a significant hypoglycaemia is stated in the related extremity left behind intense oscillations. This ischaemic hypoglycaemia reflects an extensive consumption of glucose in the cell for producing energy by anaerobic glycolysis. This appears in an increase of lactate concentrations (14). At the same time, the glycogen of the muscle is especially reduced. This obviously results from the regeneration of $3 \mathrm{~mol}$ ATP from ADP per mol glucose during the anaerobic catabolism of muscle glycogen, whereas blood glucose must first of all be phosphorylated in the muscle cell with the consumption of ATP and producing only $2 \mathrm{~mol}$ 
ATP per mol glucose. The decrease of glucose concentrations during ischaemia, however, indicates that glucose catabolism exceeds the liberation of glucose from the glycogen depots. The proof that the reactions catalysed by the phosphotransferases and acting as part of the ATP-system are responsible for the oscillations of the glycolysis was furnished by Hess (1). The hypoglycaemia is so much a common depression of metabolism; it rather represents the effort of cell to win energy by the way of a forced anaerobic glycolysis which is limited by reason of substrate deficiency. The simultaneous hyperglycaemia in the general circulatory system arises from an increased glycolysis contributorily caused by stressinduced adrenalin release. As is well known adrenalin evokes a catabolic effect on carbohydrate metabolism by mobilizing the liver glycogen via the activation of the adenylcyclase.

On the one hand limiting values are reached within these mechanisms, which cause and explain the oscillations as symptoms fo counterregulation and feed-back. On the other hand the evidence of an individual temporary disposition becomes apparent in this case and more obviously in the conduct of circadian rhythms: Daytime-dependent adjustment of the disturbed physiological equilibrium and the stability of the rebuilt regulation after the derangement of the basic rhythm by ischaemia or glucose injection refer as well as the individual-specific occurrence of different oscillations during the period of regeneration.

For the maintenance of such processes either a central oscillator or a combination of several oscillators is required. Cell studies having shown (4) that quite a number of oscillatory processes exist in the cell, and it would appear that man has many thermodynamic force machines rather than a single, central, cyclically operating one. In order to coordinate the activity, the individual oscillating forces must be linked. Whithin an individual cell this linkage takes place through proportionate metabolic pools of reaction partners, as is generally the case. In the linkage of real, non-linear oscillators their combination shows remarkable properties, as e.g. the confluence of common frequencies and phases. They represent a certain synchronization (15).

Owing to his involvement with periodic as well as accidental outside influences, it cannot be expected in man that he shows only one oscillation frequency in his thermodynamic processes. One should rather expect a whole collection of forces which potentiate themselves so that certain preferred frequencies can be found. From the physical point of view the forcefrequency spectrum of the metabolism should represent individual spectral lines rather than a continuous spectrum, each line representing a frequency estabilished by the superimposition of constellations or oscillator groups. This frequency is considerably more stable than that of a single oscillator so that the "biological clock" in relation to individual biochemical processes is much more accurate and specific for the individual. Nevertheless it must be emphasized, however, that it is not an efficient chronometric system, since it cannot enable an organism to effect absolute timing (16). The frequency of oscillations is dependent on pathways producing energy by the synthesis of ATP. Therefore, it is not independent of other metabolic events.

\section{References}

1. Hess, B. (1973), in Technische Biochemie (Rehm, H. J., Ed.), Dechema-Monographie Bd. 71, 261-276, Verlag Chemie, Weinheim.

2. Achs, M. J. \& Garfinkel, D. (1968), Comput. Biomed. Res. 2, 92-110.

3. Anderson, G., Kologen, Y. \& Papadopoulos, C. (1967), Metabolism 16, 586-596.

4. Goodwin, B. C. (1963), Temporal Organization in Cells, Academic Press, New York.

5. Walter, C. F. (1970), J. Theor. Biol. 27, 259-272.

6. Hess, B. \& Boiteaux, A. (1971), Ann. Rev. Biochem. 40 237-258.

7. Chance, B. \& Schoener, B. (1964), Biochem. Biophys. Res. Commun. 17, 416-423.

8. Chance, B., Schoener, B. \& Elsaesser, S. (1965), J. Biol. Chem. 240, 3170-3181.
9. Kawerau, E. (1966), this J. 4, 224-232.

10. Kawerau, E. \& Surtees, S. J. (1966), this J. 4, 237-247.

11. Kruse-Jarres, J. D. (1969), Klin. Wochenschr. 47, 10791084.

12. Halberg, F. (1959), Z. Vitamin-, Hormon- u. Fermentforsch. $10,225-296$.

13. Aschoff, J. (1963), Deut. Med. Wochenschr. 88, 1930-1937.

14. Karpf, M. (1974), Habilitationsschrift, Med. Fakultät Freiburg, 102-106.

15. Aschoff, J. (1964), in Biologische Periodik als selbsterregte Schwingung, Heft 138 d. Arbeitsgemsch. f. Forschung des Landes Nordrhein-Westfalen (Brandt, L., Ed.), 51-76, Westdeutscher Verlag, Köln.

16. Betz, A. (1968), in Quantitative Biology of Metabolism (Locker, A., Ed.), 205-215, Springer-Verlag, Berlin-Heidelberg-New York.
Priv. Doz. Dr. J. D. Kruse-Jarres

Chirurgische Univ. Klink

Hugstetter Str. 55

D-7800 Freiburg 